УДК 37.022

DOI $10.21661 / \mathrm{r}-467526$

\title{
A.A. Мартынюк
}

\section{ИНТЕГРИРОВАННЫЙ ПОДХОД ПРИ ОБУЧЕНИИ ПРОГРАММИРОВАНИЮ В СРЕДНЕЙ ШКОЛЕ}

Аннотация: в статье рассмотрен интегрированный подход к обучению программированию с использованием технологий компьютерного моделирования и 3D-графики, позволяющий повысить качество обучения. Показано, что данный метод позволит систематизировать знания, повысить уровень мотивачии за счет включения актуальных технологий, сформировать навыки проектной деятельности, усилить межсредметные связи, а также содействует профессионально-личностному самоопределению учеников средней школь.

Ключевые слова: обучение, программирование, метод, моделирование, графика, технологии, мотивачия, проект.

\section{A.A. Martynyuk}

\section{THE INTEGRATED APPROACH TO TEACHING PROGRAMMING IN SECONDARY SCHOOL}

Abstract: the article considers an integrated approach to teaching programming with the use of technologies of computer modeling and 3D-graphics, allowing to improve the quality of education. It is shown that this method will allow you to systematize knowledge, improve the level of motivation through the inclusion of relevant technologies, to develop skills of project activities, to strengthen interdisciplinary connections, and promotes professional and personal self-determination of students of secondary school.

Keywords: training, programming, method, modeling, graphics, technology, motivation, project. 
В современном мире информационно-коммуникационных технологий знание языка программирования является одной из базовых составляющих информационной культуры человека. Ситуация складывается также, как и с владением иностранным языком. Человек может не работать переводчиком, но знание иностранного языка становится одним из компонентов общей культуры индивидуума. Поэтому известная цитата академика Ершова, что: Программирование вторая грамотность, становиться все более актуальной в наше время тем более что информационные технологии проникли практически во все сферы деятельности человека. Особенно актуальным становится знание языка программирования если человек желает связать свою деятельность с IT индустрией.

Умение программировать позволяет развивать универсальные учебные действия, активирует мотивацию учащихся, усиливает межпредметные связи, воспитывает в учениках аккуратность, умение работать в команде, что соответствует не только основным требованиям ФГОС СОО [3], но и приветствуется работодателями.

Накопленный опыт по обучению программированию достаточно обширен, но в такой быстроразвивающейся и изменяющейся дисциплине как информатика появляются все новые и новые средства обучения, которые могут сильно изменить картину процесса образования, но остаются без внимания педагогической общественности.

Современные ученики усваивают огромный объем знаний. Естественно у них срабатывает механизм защиты организма от перегрузки. В результате мы видим такое явление как клиповое мышление. Как следствие:

1. Падает общий уровень успеваемости.

2. Снижается уровень усвоения знаний.

3. Ребенок не может сконцентрироваться на информации, у него снижается способность к анализу и синтезу.

4. При этом дети видят явное несоответствие между тем, чему учат в курсе программирования и тем, что им понадобится в дальнейшей жизни. 
Это порождает неспособность применять полученные знания в реальной жизни.

Необходимость снятия вышеперечисленных противоречий ставит перед учителем вопрос: как следует построить обучение программированию чтобы оно соответствовало требованиям ФГОС и подготовило учеников к последующей учебной, профессиональной деятельности?

Возможным вариантом решения проблемы является объединение элементов таких разделов информатики как моделирование, алгоритмизация, программирование и компьютерная графика в один интегрированный курс на основе изучения и применения интегрированных объектно-ориентированных сред программирования. При этом такая среда не должна углубленно нагружать ученика программированием мелких деталей, но при этом их учитывать.

Интегрированный подход к обучению программированию с внедрением компьютерного моделирования и трехмерной графики может стать эффективным средством обучения. Такой подход включает визуализацию, интерактивность, помогает ученикам развить способности в построении моделей и понимании научных концепций. Особенно это целесообразно в проектной деятельности, где ученик проходит все стадии проектирования: от технического задания до защиты проекта.

Персональный компьютер давно превратился из обычного калькулятора в мощное средство информационного моделирования. При этом все информационные модели представляют собой комплекс взаимопроникающих элементов, находящихся в разных содержательных линиях. Так или иначе, когда мы говорим о программировании, мы предполагаем, что программа осуществляет алгоритм, который в свою очередь является частью информационной модели. Такой информационной моделью может быть модель солнечной системы или шагающий механизм Чебышева. И становиться очевидным, что простая визуализация чисел от такой программы мало информативна.

Известный факт, что более $80 \%$ информации мы получаем через зрение и как сказал русский математик А.Д. Александров: окружающий мир - это мир 
геометрии. Вычеркните визуализацию и модель потеряет треть своей привлекательности. Кроме того, интеграция трехмерной графики развивает пространственное мышление, дает первоначальные навыки CAD проектирования, что является привлекательным для работодателей.

Что касательно программирования, классическим вариантом обучения непосредственно программированию на текущий момент является использование процедурных языков. Это вполне оправдано, поскольку процедурные языки наиболее близки к алгоритмическим конструкциям. Однако в большинстве учебников дается описание окружающего мира как иерархии систем. В своих трудах М.П. Лапчик подчеркивает, что такой подход связан с объектно-ориентированной парадигмой информационного моделирования [2, с. 323] и подчеркивает, что все современные системные и прикладные программные продукты имеют объектно-ориентированный интерфейс [2, с. 465].

С профессиональной точки зрения, при выборе изучения языка программирования мировая общественность ориентируется на рейтинг PYPL [5] и индекс TIOBE [6], в которых ежегодно анализируется популярность языков программирования, и среди рейтинговых языков мы не найдем ни одного процедурного языка. Становится очевидной задача перехода к такой методике обучения программированию, которая была бы мультипарадигмальной. Такая методика позволила бы освоить и базовые понятия об алгоритмических конструкциях и реплицировать эти понятия в актуальные языки программирования, востребованные на рынке. Кроме того, в последних версиях КИМ ОГЭ появилось два мультипарадигмальных языка: Python и C++. Согласно вышесказанному оптимальным выбором является язык JavaScript.

Если выбор языка программирования хотя и будет оставаться спорным вопросом, он не настолько сложен как выбор среды разработки. Компании по разработке ПО предлагают нам огромный выбор различных сред. К сожалению большинство таких сред узконаправленны либо на программирование, либо на CAD разработку. Кроме того, как правило, такие среды являются достаточно до- 
рогими с экономической точки зрения. Для реализации интегрированного подхода нам нужна такая среда, которая позволила бы и программировать, и создавать графические модели (желательно не только 2D, но и 3D). Плюс ко всему эта среда должна иметь низкий «уровень вхождения», чтобы дети, которые не знакомы с программированием и графикой могли достаточно быстро освоить азы работы с программой.

Анализ достаточно большого количества, предложенного на рынке программного обеспечения, выявил одну из таких сред.

Unity3D изначально создавался как инструмент для создания двух- и трехмерных приложений и игр, но со временем (2005-2015 гг.) стал позиционироваться как интегрированная мультиплатформенная среда разработки.

Эта среда представляет собой с одной стороны 3D конструктор, так как имеется CAD подобная среда редактирования с удобным интерфейсом, позволяющая визуализировать элементы проекта, с другой стороны является графическим интерфейсом пользователя для создания программ.

Unity имеет полный набор качеств профессионального приложения [4]:

- интегрированный графический редактор. Интерфейс редактора подобен AutoCAD, Blender и др.;

- Unity поддерживет все основные форматы графических файлов и файлов 3D моделей;

- в Unity есть поддержка DirectX и OpenGL;

- инструменты фотореалистичной 3D визуализации (тени и свет);

- скриптовые языки JavaScript и C\# на основе.NET с библиотеками и великолепной документацией.

- работа с сетью;

- поддержка аудио и видео;

- система хорошо документирована и есть пошаговые уроки, проекты-примеры;

- мультиплатформенность позволяет создавать приложения для операционных систем Windows, OS X, Android, Linux, а также для игровых приставок Wii, 
PlayStation, Xbox и MotionParallax3D дисплеях (устройства для воспроизведения виртуальных голограмм), смарт TV. Разработанные приложения можно запускать в браузерах с помощью специального подключаемого модуля Unity Web Player, а также с помощью реализации технологии WebGL;

- возможность создавать приложения для устройств виртуальной реальности.

Технология дополнительной реальности имеет огромный потенциал для расширения сферы использования компьютерной техники. Существенными являются ее образовательный потенциал и значимость для расширения возможностей систем обучения информатике [1, с. 94].

Используя современный объектно-ориентированный язык, 3D-графику, навыки создания математических моделей ученик научится не только работе в актуальных средах разработки, но и за счет формирующихся межпредметных связей укрепит научное мировоззрение.

Таким образом, считается целесообразным применение интегрированного подхода путем объединения в процессе обучения программированию, на базе объектно-ориентированного языка, элементов компьютерного моделирования и трехмерной графики и применения мультиплатформенной среды разработки Unity. Это позволит реализовать продуктивные методы и формы обучения, повысить мотивацию обучения за счет использования современных средств разработки программного обеспечения, повысить уровень восприятия информации, сформировать умения реализовывать проекты в учебной деятельности.

\section{Список литературы}

1. Вестник МГПУ. Журнал Московского городского педагогического университета. Серия «Информатика и информатизация образования». - 2016. №4 (38). - C. 108.

2. Лапчик М.П. Теория и методика обучения информатике: Учебник / М.П. Лапчик, И.Г. Семакин, Е.К. Хеннер, М.И. Рагулина [и др.]; под ред. М.П. Лапчика. - М.: Издательский центр «Академия», 2008. - 592 с. 
3. Об утверждении государственного образовательного стандарта среднего общего образования: приказ Минобрнауки России от 17.05.2012 №413, зарегистрирован в Минюсте России 07.06.2012 №24480 (начало публикации) // Вестник образования России. - 2012. - №14. - С. 37-38; №15. - С. 35-40. - См. также // ОДО. - 2012. - №20, 21; Вестник образования. - 2012. - №13; Администратор образования. - 2012. - №15. - С. 12-56.

4. Руководство пользователя Unity [Электронный ресурс]. - Режим доступа: http://docs.unity3d.ru (дата обращения: 29.11.2017).

5. PYPL PopularitY of Programming Language. [Электронный ресурс]. - Peжим доступа: http://pypl.github.io/PYPL.html (дата обращения: 29.11.2017).

6. TIOBE Software BV [Электронный pecypc]. - Режим доступа: https://www.tiobe.com/tiobe-index/ (дата обращения: 29.11.2017).

\section{References}

1. (2016). Vestnik MGPU. Zhurnal Moskovskogo gorodskogo pedagogicheskogo universiteta. Seriia "Informatika i informatizatsiia obrazovaniia", 4 (38), 108.

2. Lapchik, M.P., Semakin, I.G., Khenner, E.K., \& Ragulina, M.I. (2008). Teoriia i metodika obucheniia informatike, 592. M.: Izdatel'skii tsentr "Akademiia".

3. (2012). Ob utverzhdenii gosudarstvennogo obrazovatel'nogo standarta srednego obshchego obrazovaniia: prikaz Minobrnauki Rossii ot 17.05.2012 413, zaregistrirovan v Miniuste Rossii 07.06.2012 24480 (nachalo publikatsii). Vestnik obrazovaniia Rossii, 14, 37-38.

4. Rukovodstvo pol'zovatelia Unity [Electronic resource]. - Access mode: http://docs.unity3d.ru

5. PYPL PopularitY of Programming Language [Electronic resource]. - Access mode: http://pypl.github.io/PYPL.html

6. TIOBE Software BV [Electronic resource]. - Access mode: https://www.tiobe.com/tiobe-index/ 
Мартынюк Алексей Анатольевич - технический специалист ГБОУ г. Москвы «Пушкинская школа №1500», Россия, Москва.

Martynyuk Aleksej Anatolevich - technical specialist at State Budgetary Educational Institution of Moscow «Pushkin School №1500», Russia, Moscow. 